\title{
Reducing the Water Hardness by Using Electromagnetic Polarization Method
}

\author{
Ghassan Hassan Abdulrazzaq \\ Department of Petroleum processing Engineering/College of Petroleum \& Minerals Engineering/Tikrit University \\ Email:ghassanaldoori@yahoo.com
}

(Received 20 March 2016; accepted 24 July 2016)

http://dx.doi.org/10.22153/kej.2016.07.002

\begin{abstract}
Hard water does not pose a threat to human health but may cause precipitation of soap or results stone in the boilers. These reactions are caused by the high concentrations of $\mathrm{Ca}$ and $\mathrm{Mg}$. In the industry they are undesirable because of higher fuel consumption for industrial use .Electromagnetic polarization water treatment is a method which can be used for increasing the precipitation of $\mathrm{Ca}^{2+}$ and $\mathrm{CO}_{3}{ }^{2-}$ ions in hard water to form $\mathrm{CaCO}_{3}$ which leads to decrease the water hardness is research has been conducted by changing the number of coil turns and voltage of the system. The spectroscopy electron microscope was used for imaging the produced crystals. Results of the investigation indicated that the electromagnetic polarization can be used in precipitation to decrease the hardness of water due to increase in the precipitation percent of $\mathrm{CaCO}_{3}$.
\end{abstract}

Keywords : Electromagnetic polarization, water hardness, $\mathrm{CaCO}_{3}$.

\section{Introduction}

Water hardness is a measure of the capacity of water to its reaction with soap. Hard water causes more soap foaming. The reason for this is not a single substance, but a diverse dissolved polyvalent metal ions, mainly cautions of calcium, and magnesium, although much less contributing and other cautions, e.g., barium, iron, manganese, strontium and zinc.

Hardness is usually expressed in $\mathrm{mg} / \mathrm{L}$ $\mathrm{CaCO}_{3}$, the German, French and English Degrees of hardness are expressed as follows :

1. German hardness $=10 \mathrm{mg} \mathrm{CaO}$ in 1 liter of water

2. French degree of hardness $=10 \mathrm{mg} \mathrm{CaCO}_{3}$ in liter of water

3. English hardness $=10 \mathrm{mg} \mathrm{CaCO}_{3}$ in 0.7 liters of water.

Because the distribution of the earth's crust, magnesium is present in natural waters, where together with calcium makes total hardness of water. The concentrations of $\mathbf{M g}$ ions are particularly high in the area dominated by dolomite rocks. This is the case of ground water in the vicinity of Tikrit university. In this area, natural waters are characterized by a high content of magnesium, whose concentration can be up to $200 \mathrm{mg} / \mathrm{dm}^{3}$, which makes them unfavorable for use in the public water supply, since the maximum concentration of magnesium in drinking water according to current regulations is limited to $50 \mathrm{mg} / \mathrm{dm}^{3}$ [1].

In the experiments presented in this paper the reduction of the concentration of magnesium in the water that flows into an abandoned mine shaft "undermine" is discussed. This water has shown a stable composition and a negligible presence of microorganisms, and as such has been introduced in the water supply system in the vicinity of Tikrit city . The only drawback is the high content of magnesium, which ranges up to $100 \mathrm{mg} / \mathrm{dm}^{3}$. However, as the river water has variable composition, that is, it often causes reduction the quality of raw water, thereby the consumption of 
large amounts of coagulants and flocculants to ensure its physical and chemical safety is increased[3]. The total solute (Total Dissolved Solids) of inorganic salts are dissolved in water with. Unit of milligram per liter ( $\mathrm{mg} / \mathrm{l})$. The majority of salts consisting of cautions of calcium, magnesium, sodium and potassium, and anions are carbonate, bicarbonate, chloride, sulfate and nitrate. The dissolved substance introduced can affect its taste. On the basis of the measured values the palatability of the drinking water is evaluated. Table (1) shows some parameters of water [4].

Table 1, parameters of water hardness.

\begin{tabular}{lll}
\hline Water & $\begin{array}{l}\text { mg } / \mathbf{L} \\
\mathbf{C a C O}_{3}\end{array}$ & $\begin{array}{l}\text { German degrees } \\
\mathbf{d}\end{array}$ \\
\hline Soft & $<71.4$ & $<4$ \\
Easy hard & 71.4 to 142.8 & $4-8$ \\
Moderately & 142.8 to & $8-18$ \\
hard & 321.4 & \\
Hard & 321.4 to & $18-30$ \\
& 535.7 & \\
Very hard & $>535.7$ & $>30$ \\
\hline
\end{tabular}

\subsection{Background}

Water is essential raw material for industrial production, energy, food industry for communal needs and more. Most requirements for water purity set the food industry (beer, juices) and municipal systems to supply drinking water to citizens. Therefore of great importance all processes for treating raw water which must be removed, suspended solid, organic and inorganic chemical compounds, bacteria and chemicals which gives a bad taste and odor. Due to the high prices of raw water treatment, appropriate technologies must be combined as best way to establish a balance between the price and the resulting water quality. The processes to treat and recover raw water is the use of electromagnetic field. Hydrate ion interaction forces can be influenced by mechanical agitation, temperature, concentration ion and electromagnetic fields. Electromagnet field can weaken the ion and water molecules and increase the collision between the $\mathrm{Ca}^{2+}$ and $\mathrm{CO}_{3}{ }^{2-}$ ions, thus accelerating the rate of nucleation and precipitation of $\mathrm{CaCO}_{3}[5]$.

The chemical features of groundwater depende on the type and amount of dissolved mineral substances. Measure the intensity of the melting of rocks in the process, ie corrosion, is hardness water. Increased hardness is a sign of intense corrosion and vice versa. Determined in forming calcium and magnesium ions in water. Total hardness shapes all the calcium and magnesium salts in water[6].

Carbonate hardness make hydrogen carbonates and carbonates of calcium and magnesium. The calcium and magnesium hardness values and relationship depend on the composition of the rocks through which water flows. Groundwater generally is stiffer than surface water. The concentration of minerals in groundwater increases with length of detention or the flow of water through underground cavities[7].

Some studies about the water reported that Water hardness can be divided into:

- $\quad$ carbonate hardness, comes from Ca and Mg ions in the form of bicarbonate

- $\quad$ Non-carbonate hardness, comes from Ca and $\mathbf{M g}$ ions in the form of sulphates, chlorides and nitrates.

- $\quad$ Boiling water bicarbonates is converted into carbonates, which are insoluble in What disappears carbonate hardness, left non-carbonate (permanent) hardness.

- The waters are classified into four levels of hardness, if hardness is expressed in $\mathrm{mg} / \mathrm{L}$ $\mathrm{CaCO} 3[8]$.

\section{Methodology}

The principle of this method is to provide an electromagnetic field with certain frequencies in the hard water that flows through a coil with a certain winding number that can promote the process of precipitation of $\mathrm{CaCO}_{3}$.

This creates small seed crystals in water in the form of very small particles of calcium carbonate prior to entry of the water zone at high temperature. Calcium carbonate adheres to the surface of these very small particles and grow in size. These larger particles tend to be removed by the flow . Faraday law associated with Lenz's law states that the electric field is induced in the magnetic coil when the magnetic field changes with time. The magnetic field is proportional to the current in the coil winding when current changes in coils; the alternating magnetic field is an electric field resisting these changes. This induced $\mathrm{AC}$ voltage is high on the side of inspection and tube coil decreases to nothing at the tube coil shows ionic configuration of particles in a magnetic field .Pipe center coil and the coil shown in Figure (1). 


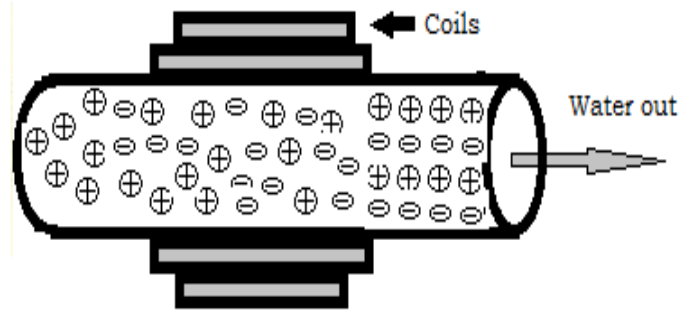

Fig. 1. Configuration of ionic particles in a magnetic field.

The carbonate ions $\mathrm{CO}_{3}{ }^{-2}$ will react with calcium ions $\mathrm{Ca}^{+2}$, and the result will produce some precipitation and crystallization of calcium carbonate .as illustrated in equation number (1) [9] :

$\mathrm{Ca}+2+\mathrm{CO}_{3}^{-2} \rightarrow \mathrm{CaCO}_{3}$

\subsection{Experimental Work}

Treatment Process had been conducted by mixing the prepared solution $(50 \mathrm{ml})$ for about 10 minutes with rate of $(19.02 \mathrm{ml} / \mathrm{s})$, the solution temperature equals to the room temperature $\left(25^{\circ}\right.$ C) as follows:

1. EWT system used consisted of copper pipe wrapped with copper wire and Power supply as shown in figure (1). Sample of hard water is circulated through the electromagnet field using silicon tube (ID $6 \mathrm{~mm}$ ) and peristaltic pump as shown in Figure (2).

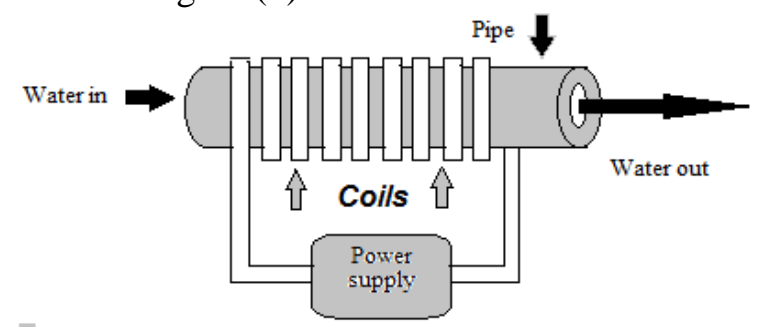

Fig. 2. Schematic of electromagnet Equipment.

2. After the EWT treatment, solution in the reservoir tube again was introduced to the testing process to measure the content of $\mathrm{Ca}^{+2}$ ions contained in the solution and to examine the type and number of crystals formed.

3. The average values of $\mathrm{CaCO}_{3}$ concentration for the two cases ,before and after electromagnetic field water treatment were cpmpared .

\section{Results and Discussion}

A- Figure (3) shows the effect of voltage changing on the precipitation of $\mathrm{CaCO}_{3}$. An increasing in the applied voltage will cause some increasing in the precipitation percent of $\mathrm{CaCO}_{3}$. Any increasing in the voltage will cause some increasing in the current through the solenoid coil on EWT tool. This will increase the induction of electromagnetic fields on water according to Faraday's law. As a result the increased induction of electromagnetic fields will improve the effectiveness and impact energy between the ions of $\mathrm{Ca}^{+2}$ and $\mathrm{CO}_{3}{ }^{-2}$ in solution so that the rate of precipitation of $\mathrm{CaCO}_{3}$ increases. Results of changing the voltage source are shown in table (2) and the graphical representation is shown in Figure (3).

Table 2,

Applied voltage vs. percentage of $\mathrm{CaCO}_{3}$ precipitation .

\begin{tabular}{ll}
\hline Voltage (v) & $\mathbf{C a C O}_{3}$ Precipitation \% \\
\hline 1 & 14 \\
2 & 15 \\
3 & 17 \\
4 & 19 \\
5 & 20 \\
6 & 22 \\
7 & 24 \\
8 & 27 \\
9 & 28 \\
10 & 13 \\
11 & 33 \\
12 & 35 \\
\hline
\end{tabular}

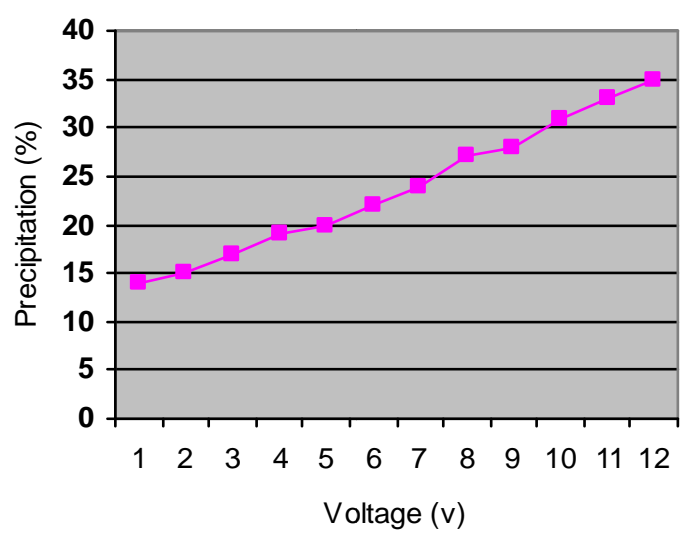

Fig. 3. Effect of voltage source changing on precipitation of $\mathrm{CaCO3}$.

B- From figures $(4,5)$ it can be seen that the precipitation of $\mathrm{CaCO}_{3}$ is increased when voltage is duplicated . 


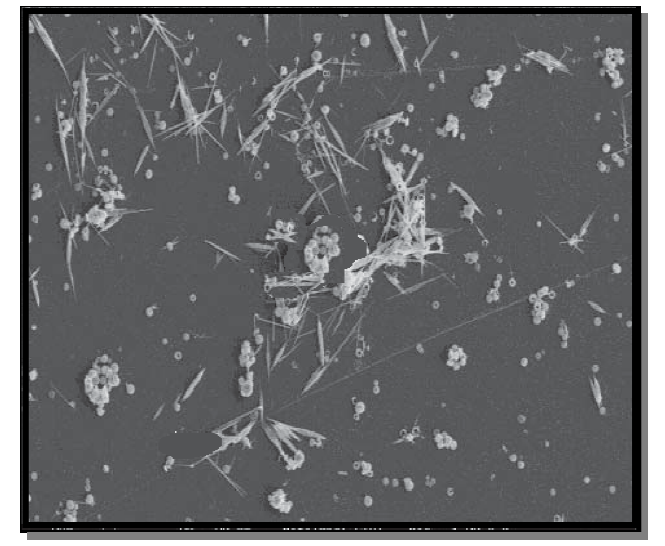

Fig. 4. (A) : Precipitation of $\mathrm{CaCO3}$ when voltage source of $(6 \mathrm{~V})$.

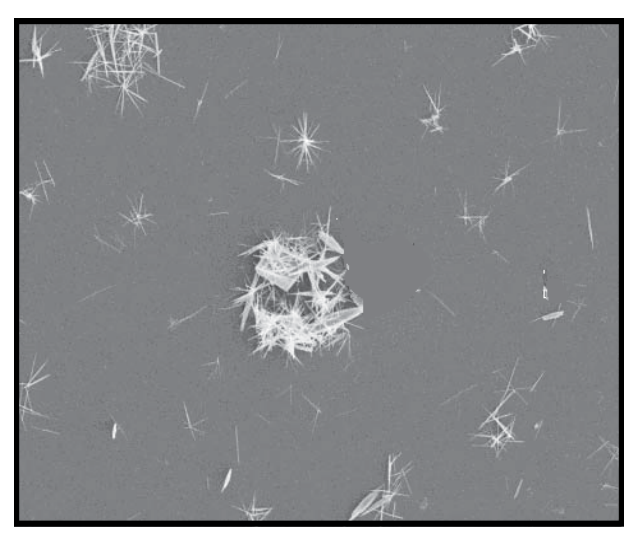

Fig . 5. Precipitation of $\mathrm{CaCO3}$ when voltage source of $(12 \mathrm{~V})$.

C- Results of changing the turns number are shown in table (3) and the graphical representation is shown in Figure(6).

Table 3,

Number of turns vs. Percentage of $\mathrm{CaCO3}$ precipitation.

\begin{tabular}{ll}
\hline Number of turns & $\mathrm{CaCO}_{\mathbf{3}}$ Precipitation \% \\
\hline 50 & 24 \\
100 & 32 \\
150 & 35 \\
200 & 39 \\
250 & 43 \\
\hline
\end{tabular}

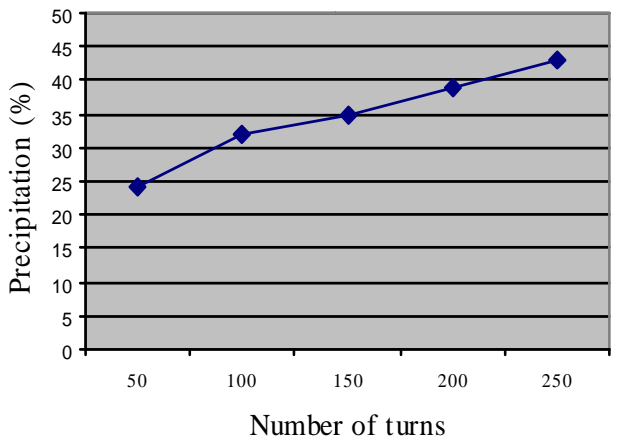

Fig. 6. Effect of changing the number of turns on the precipitation of $\mathrm{CaCO3}$.

D - The greater the number of turns are used, the larger electromagnetic fields induced received by the water hardness in the coil. This has an impact on increasing the effectiveness of collisions between $\mathrm{Ca}{ }^{2+}$ and $\mathrm{CO}_{3}{ }^{2-}$ ions thereby increasing the precipitation of $\mathrm{CaCO}_{3}$.Figures $(7,8)$ shows the increasing percent of the precipitation of $\mathrm{CaCO}_{3}$ with increasing the number of turns.

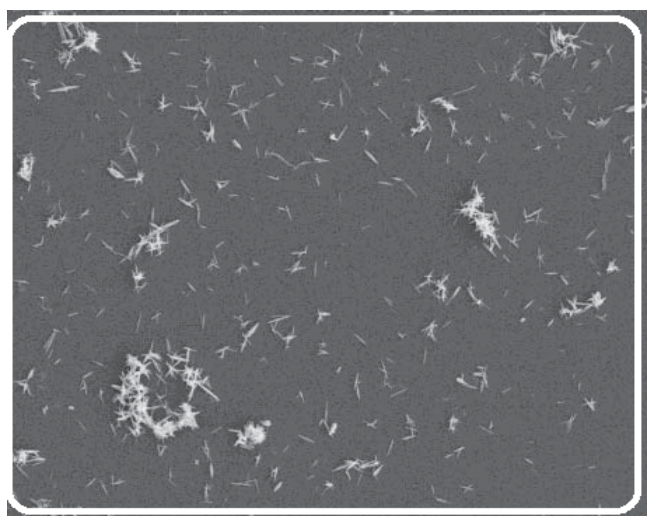

Fig. 7. Precipitation of $\mathrm{CaCO3}$ when coil with 100 turns.

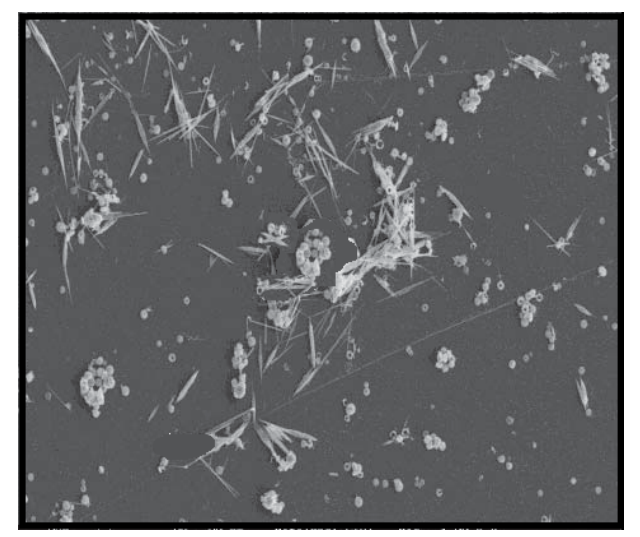

Fig. 8. Precipitation of $\mathrm{CaCO}_{3}$ when coil with 250 turns 


\section{Conclusion}

Depending on where the rain falls, the water remains naturally soft, or becomes contaminated with various contaminants. Water is the best solvent, and as it passes through the soil it, collects various pollution. No method for purifying water can produce laboratory water cleaned of all contaminants. Only a combination of effective and economical method can produce satisfactory laboratory water quality. For high efficiency treatment water is used in combination of several methods .Results showed that the electromagnet field affected an increase in the precipitation amount of $\mathrm{CaCO}_{3}$ up to $34 \%$ compared to non electromagnetic fields. Increasing the voltage, the number of turns of coil causes an increase in precipitation $\mathrm{CaCO}_{3}$. Increasing the electromagnetic field levels caused the $\mathrm{CaCO}_{3}$ particle to unit with each other to form larger groups. The benefit of this method is in the reduction or elimination of chemical additives method.

\section{References}

[1] Patrons, S. A., Judd, S. J., Stephenson, T., Udol, S., and Wang, B. L. (1997). Magnetically augmented water treatment. Inst. Chem. Eng. 75(B2), 98-104.

[2] Gehr, R., Zhai, Z. A., Finch, J. A., and Fao, S. R. (1995). Reduction of soluble mineral concentrations in $\mathrm{CaSO} 4$ water using a magnetic field. Water. 29,933-940.
[3] Arnedo-Pena A, C (2007). "Domestic water hardness and prevalence of atopic eczema in Castellon (Spain) school children". Salud Publica Mex. 492 (4): 295-301

[4] Cho, Y.I.,et al. (1997). Theory of electronic anti-fouling technology to control precipitation fouling in heat exchangers. Heat Mass Transfer. 24, 757-770.

[5] Bott T. R., The Fouling of Heat Exchangers, Elsevier Science, New York, (1995)

[6] Muller-Steinhagen, H. (1999). Cooling Water fouling in heat exchangers. In "Advances in Heat Transfer", Vol. 33, pp.415-496. Academic Press, New York .DREYBRODT,

[7] EISENLOHR, L. (2000.): Limestone Dissolution Rates in Karst Environments. U:Klimchouk, A., Ford, D., Palmer, A., Dreybrodt, W. (ur.): Speleogenesis. Evolution of Karst aquifers, National speleological society, Huntsville, 136-148. FORD, D., WILLIAMS P. (1989.): Karst Geomorphology and Hydrology,

[8] Cho Y. I., (2002). Efficiency of physical water treatment in controlling calcium scale accumulation in recirculating open cooling water system, ASHRAE Research Project 1155-TRP.

[9] Tijing, L. D., et al, An experimental study on the bulk precipitation mechanism of physical water treatment for the mitigation of mineral fouling, International Communication in Heat and Mass Transfer, 34, (2007), 673-681. 


\title{
تقليل عسرة المياه بطريقة الاستقطاب الكهرومغناطيسي
}

\author{
غسان حسن عبد الرزاق

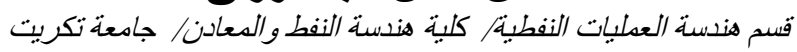 \\ ghassanaldoori@yahoo.com: البريد الالكتروني لناني
}

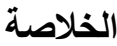

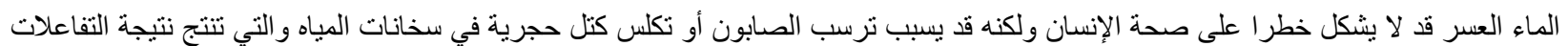

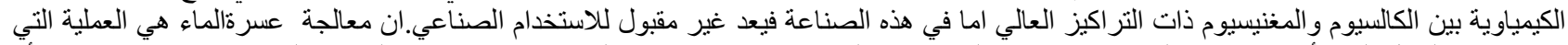

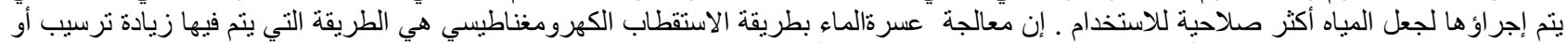

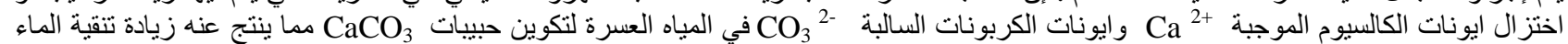

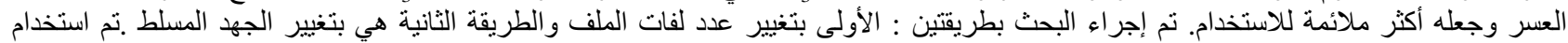

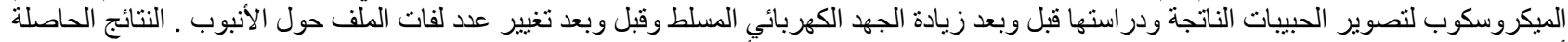

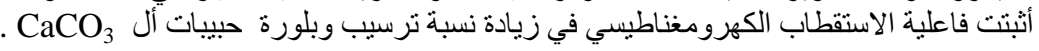

